\title{
Measuring the Effects of Emotional Intelligence, Cultural Intelligence and Cultural Adjustment on the Academic Performance of International Students
}

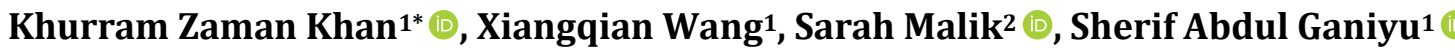 \\ ${ }^{1}$ School of Economics and Management, Anhui University of Science and Technology, Huainan, China \\ ${ }^{2}$ School of Business Administration, COMSATS University, Islamabad, Pakistan \\ Email: ^Khurramzk@outlook.com,xqwang@163.com, its.sarah.malik@gmail.com, abdulganiyusherif1@gmail.com
}

How to cite this paper: Khan, K. Z., Wang, X. Q., Malik, S., \& Ganiyu, S. A. (2020). Measuring the Effects of Emotional Intelligence, Cultural Intelligence and Cultural Adjustment on the Academic Performance of International Students. Open Journal of Social Sciences, 8, 16-38. https://doi.org/10.4236/jss.2020.89002

Received: July 31, 2020

Accepted: August 29, 2020

Published: September 1, 2020

Copyright $\odot 2020$ by author(s) and Scientific Research Publishing Inc. This work is licensed under the Creative Commons Attribution International License (CC BY 4.0).

http://creativecommons.org/licenses/by/4.0/

cC) (i) Open Access

\begin{abstract}
Purpose: The purpose of this research is to study the effects of emotional intelligence and cultural intelligence of undergraduate, graduate, and post graduate students studying abroad and how it affects their academic performance, with cultural adjustment mediating their educational achievements. Methodology: We employed the use of closed-ended questionnaire and distributed them among a sample of 222 respondents. 202 questionnaires were returned that were useful. IBM SPSS 25.0 and Andrew F. Hayes process 3.5 was used to analyze the results of the survey. Cronbach's alpha was used to determine the reliability of the study and multiple regression analysis and Pearson's correlation was used to determine the significance of the variables in relation with each other. Result and Findings: Analysis of the data for our study reveals that all variables were statistically significant, positive and moderately correlated with each other and cultural adjustment significantly mediates the effect between emotional intelligence, cultural intelligence and academic performance of international students. Research Implication: This study seeks to add to the already existing literature on how cultural intelligence, emotional intelligence and cultural adjustment impact on the academic performance of international students studying abroad. Moreover, this research can be used as a framework by educational institutions such as universities in determining how well international students are adjusted in their new environment and how these factors influence their academic performance over time. Limitations: The study was conducted on a cross-sectional basis, and the results were based on quantitative analysis alone. Future Research: Further studies can employ a longitudinal research of the variables and measure the effects over time. Moreover, a qualitative analysis can help in gaining a
\end{abstract}


better understanding of the students and their academic performance. A larger sample size can be used that contains a more diversified audience.

\section{Keywords}

Emotional Intelligence, Cultural Intelligence, Cultural Adjustment, Academic Performance

\section{Introduction}

The world as we know it is a lot smaller than it was 20 years ago. Due to the expansion of technology, the general exposure to information and increase in world travel, the entire earth has now become a global village. This expansion, in turn, gave rise to international exchange of students as well, with students moving to foreign countries for higher education, and trade of technology and skill (Nasir, 2012). Any student obtaining education in an overseas country comes face to face with a lot of difficulties and is met with a culture shock, since it is a new environment with unfamiliar rules and regulations than his/her own home country. The culture shock can range from a new language to an entirely different set up regarding every minute things including non-verbal behavior, food, social gatherings, clothes etc.

International students have their own distinctive set of beliefs and values they bring from their home country that differs from their hosts. This difference might create problems and clashes for the student that results in adjustment issues and emotional problems. This explains why there is a certain adjustment period before all the issues related to cultural difference are resolved.

Previously, the only form of intelligence was Intelligence Quotient (IQ), but since 1936 new forms of intelligence have appeared as well (Thorndike, 1936). One of them is Social Intelligence (SI) whose sub-category includes Emotional Intelligence (EI). It is described as one's capability to regulate instincts, postpone satisfaction, control temper, empathize, and experience optimism (Goleman, 1995). Another form of intelligence that has recently emerged since the world turning into a global village is Cultural Intelligence (CI). It is described as one's ability to work and cope successfully in a socially different environment (Ang et al., 2007). Hence, these variables are also put to work in order to analyze the students' capabilities and how they affect other variables and their outcomes.

This study aims to reveal the relationship between international students' cultural intelligence, emotional intelligence, cultural adjustment and academic performance. More importantly, this research seeks to study and define the underlying relationships between the measurement variables and the academic outcome of international students in foreign countries by the use of correlation analysis and regression analysis.

This research is organized as follows: Section 1 consists of the introduction of the study, Section 2 presents literature review on International students' emo- 
tional intelligence, cultural intelligence, cultural adjustment and academic performance. The methodology used in this research is presented in Section 4 and Section 5 ends the research as conclusion.

\section{Literature Review}

\subsection{Emotional Intelligence (EI)}

First, EI emerged as a subset of social intelligence which was originally propounded by Thorndike (1920). After the emergence of this domain, further researchers studied this topic in order to identify more domains of intelligence. Salovey and Mayer (1990) also put forward one of such domain and named it emotional intelligence. After its development, it gained popularity and started attracting different and contrasting opinions from different scholars (Cartwright and Pappas, 2008). EI is defined as social intelligence's sub-element that involves the capability of humans to understand their emotions, monitor others' emotions, and make use of this knowledge to control and direct their own perceptions and behavior (Salovey and Mayer, 1990). Goleman (1995) said that EI is made up of the capabilities which can be classified under awareness of oneself, control of emotions, encouraging oneself, compassion and managing relationships. Goleman (1996) further refined his definition in 1996 stating that EI is composed of skills that involve an individual's capability to perform, work in groups and adapt, as and when necessary, in doing so. Agreeing with his point of view, Salovey and Pizarro (2003) said that emotional intelligence is the aptitude of human beings to observe, use, comprehend, communicate, and regulate their feelings as a means of adapting and improving performance. Further research on EI uncovered new elements, branches, and categories. Bar-On (2004) came up with a different model in which he said that EI contains social and emotional skills that help individuals to recognize and express ourselves, comprehend others' emotions, understand and empathize with them, and use them to deal with daily demand. Bar-On (2004) categorized EI in five major components i.e. intrapersonal component, interpersonal component, stress management, adaptability, and general mood. Evans (2007) studied EI in terms of high school students and its effect on their performance. It was found that students who used some form of self-regulation were successful academically and socially. Self-regulation was formed among students by working positively with others and later led to better social adjustment, high achievement, and empowerment (Evans, 2007). Rice (2007) conducted a study that revealed that students who lacked the elements of EI were more likely to be academically weak.

For the purpose of our research, we adapted the definition of Mayer \& Salovey (1997) that states that EI is the capability to understand, assess, express and regulate feelings and knowledge related to emotions. The 4 dimensions of EI that we will be using are that of Salovey and Mayer (1990):

- Self Emotional Appraisal (SEA): It is the capability of humans to comprehend and convey one's feelings in a natural manner. Individuals who possess 
a greater degree of SEA will be competent enough to recognize their feelings better than the ones who lack in this area.

- Others' Emotional Appraisal (OEA): It is the capability of humans to analyze, experience and recognize the feelings of those around themselves. Individuals who possess a greater degree of OEA will easily recognize the emotions of others and read their minds.

- Regulation of Emotion ( $R O E$ ): This is the capability of an individual to adjust their feelings and deal with psychological pressure.

- Use of Emotion ( $U O E$ ): This is the capability of an individual to use and apply one's feelings in a constructive manner that improves one's personal performance.

\subsection{Cultural Intelligence (CQ)}

Since the early 2000's cultural intelligence has been gaining consistent popularity. The term CQ was originally coined by Earley \& Ang (2003) in a book titled "Cultural Intelligence: Individual Interactions across Cultures". CQ is described as the ability of humans to effectively experience, understand and respond to cues in a diverse social setting and perform accordingly in that environment (Earley \& Ang, 2003). Earley \& Mosakowski (2005) defined it in different terms saying that it is the capability of a person to properly function in a socially influenced situation. Thomas \& Inkson (2004) defined CQ as a construct made up of multiple facets that include cultural knowledge, repertoire of behavioral skills, and the practice of mindfulness. Thomas (2006) defined CQ as the ability of individuals which permits them to comprehend and behave suitably when facing a multicultural setting. People who possess a higher degree of cultural intelligence adapt well to a cross-cultural setting and, in turn, perform better than those who lack in this domain. Hence, CQ is used as a variable to predict intercultural effectiveness (Abdul Malek \& Budhwar, 2013). Previous studies have highlighted $\mathrm{CQ}$ as a set of framework that includes metacognitive, cognitive, motivational and behavioral components of CQ (Ang, Van Dye, \& Koh, 2006; Ang et al., 2007; Earley \& Ang, 2003). The metacognitive and cognitive components relate to the knowledge and differences regarding different cultural contexts. The motivational and behavioral components relate to the thirst of individuals to gain knowledge and understanding regarding diverse environments and cultures, and to act accordingly.

- Metacognitive CQ: It is described as a cerebral procedure of an individual and one's capability to obtain cultural knowledge, comprehend it, and identify cultural preferences (Kim et al., 2008). People who have greater metacognitive element know in what manner to display their understanding of culture (Ang et al., 2007).

- Cognitive CQ. It is described as a general understanding about a nation, its values and beliefs, norms, rules etc. Individuals can get this knowledge through research and involvement in such an environment. Kim et al. (2008) believe that this understanding also includes the information regarding legal, 
social and economic systems of a culture. Ang et al. (2007) say that individuals who possess a greater degree of cognitive CQ are better at socializing with people who have different cultural backgrounds.

- Motivational CQ: It is defined as the drive of humans to learn about different cultures and to perform well in cross-cultural settings (Ang et al., 2007). Individuals who possess high motivational element have a higher aspiration to face the difficulties and obstacles of a new cultural environment, overcome frustration and modify themselves to fit in a different social setting.

- Behavioral CQ: It is described as people's ability to display suitable behavioral and verbal cues while socializing with individuals in a diverse social setting (Kim et al., 2008). Ang et al. (2007) held that individuals can develop better interpersonal relationships and are better welcomed by a group of people if they display the right gestures, tone, behavior, words, body language, face expressions etc.

\subsection{Cultural Adjustment}

Cross-cultural adjustment has been defined in many different ways and many different contexts. Chopra (2005) defined adjustment as changes and accommodations that help an individual to deal with a new environment. Simon, Kelichman, \& Santrock (1994) said that it is a process of absorbing problems and dealing with the challenges of everyday life. Cultural adjustment is the modifications that an individual goes through to fit into the environment of the foreign country (Gabel, Dolen, \& Cerdin, 2005). Constantine et al. (2004) defined it as an on-going process of obtaining information regarding the host culture and then integrating it in one's own behavior as perceived through one's own home country. Kagan \& Cohen (1990) asserted that it is a process that integrates the elements of cognitive, behavioral, demographic and affective aspects that are interrelated and can result in diverse degrees of adjustment from cultural assimilation to cultural transmutation. Cultural adjustment has also been defined in the context of profession and expatriates in the form of a level of ease that an overseas individual feels mentally when compared to the different dimensions of host country (Vianen, De Pater, Kristof-Brown, \& Johnson, 2004). Black (1988) indicated that cultural adjustment is the cognitive outcome of adaptation of an individual to his/her new roles and requirements in a new setting. Black et al. (1991) suggested a cultural adjustment model that pinpoints the variables that have an effect on one's adjustment to a new culture i.e. general, interaction and work adjustment. Black's (1988) three dimensional model has been the focus of research for a lot of studies regarding cultural adjustment (Parker \& McEvoy, 1993; Shaffer, Harrison, \& Gilley, 1999; Palthe, 2004). Analyzing these dimensions of adjustment is important in order to study how individuals face cultural challenges (Black et al., 1991).

- General Adjustment: It consists of the factors that an individual experiences on daily basis such as general environment, food, clothes, living conditions, health care, climate etc. 
- Interaction Adjustment. It is the degree of ease that an individual experiences when meeting with local people of a foreign country. It is the most difficult form of adjustment since every culture has its own verbal and non-verbal cues, norms, expectations, traditions etc.

- Work Adjustment. It is defined as the level of comfort an individual experiences as he/she adjusts to his/her job environment, performance standard, tasks, and roles.

\subsection{Academic Performance}

For many years, the achievement and outcome of undergraduates, graduates and postgraduates have grasped the focus of various studies (Head, 1990). In order to measure the level of student performance, different predictors of performance have been developed (Yorke, 1991). These predictors are classified as academic, cognitive, psychosocial and demographic groups (McKenzie and Schweitzer, 2001). The academic predictors were adapted for our study centralizing on current studies on academic performance. Prior academic performance can be used to predict the future achievements of a student in higher education ( $\mathrm{Li}$ et al., 2010). It has been claimed by different researchers that it holds an important place in determining a students' further success academically (McKenzie \& Schweitzer, 2001; McKenzie, Gow, \& Schweitzer, 2004). Abbott-Chapman, Hughes, \& Wyld (1992) have stated that learning habits and skills also have a great impact on achievement in academic areas. Approaches and strategies to learning have also been the focus of research regarding educational competency e.g. Watkins \& Hattie (1981) used Biggs Study Process Questionnaire (SPQ) (Biggs, 1987), while Sadler-Smith (1996) and Duff, Boyle, Dunleavy, \& Ferguson (2004) used Revised Approaches to Studying Inventory (RASI) in order to gain an understanding about the relationship among learning tactics and methods, and academic achievement. These studies resulted in a significant correlation among these two variables. Learning strategies are divided into general learning strategies and subject-matter-specific strategies. We will only be focusing on motivation and general learning strategies that include:

- Intrinsic Goal Orientation: It is the drive that branches from internal sources.

- Extrinsic Goal Orientation: It is the drive that branches from external sources.

- Self-efficacy. it is the belief that an individual has in his own capabilities to deliver the activities in order to accomplish a certain level of performance.

- Meta-cognitive Strategy. It includes organizing, observing and evaluating an individual's own perception, reasoning and understanding.

- Cognitive Strategy: It measures how well an individual can integrate and relate new information with previous knowledge (Pokay \& Blumenfeld, 1990).

\section{Research Methodology}

\subsection{Conceptual Framework}

In an attempt to measure the effect of cultural intelligence, emotional intelli- 
gence and cultural adjustment on the academic performance of international students, we propose the conceptual model below Figure 1. This model also shows the mediating role of cultural adjustment.

\subsubsection{Effects of Emotional Intelligence on Cultural Adjustment}

Recently, more and more researches are being conducted on the effect or impact of emotional intelligence on acculturation or performance of individuals in a work or non-work environment (Mount \& Downtown, 2006; Yoo et al., 2006). Previous researches have shown the relationship of EI with labor, education, health, adjustment etc. They have revealed positive relationships of EI with the adjustment of life (Chen et al., 2006), interactive behavior (Engelberg \& Sjoberg, 2004), educational achievement (Adeyemo, 2006), psychological well-being (Kerr et al., 2004), and cultural regulation (Gabel et al., 2005). Bar-On (2000) suggested that emotional intelligence can be used as a tool to explain and resolve the problems arising in a diverse cultural setting and to attain an improved cultural position. Kim et al. (2008) asserted that with the aid of emotion and information, it becomes easier for an individual to grasp cultural norms of the host nation and to interact with local people.

In contrast to these opinions, different researchers have said that having a greater measure of EI is no prediction of a better cultural adaptation (Earley and Peterson, 2004; Earley and Ang, 2003). Individuals with a higher level of EI may deal with their native culture effectively, but may be unable to transfer or apply this knowledge to cultures different from their homeland and fail to adjust and interact with the locals effectively. Marsh, Elfenbein, and Ambady (2003) agree with this point of view stating that facial expressions and body languages differ across cultures and people might fail to recognize and interpret the clues in the right manner. However, Earley and Peterson (2004) recognize that with further developing studies, it might be possible to relate EI with cross-cultural adjustment as the researchers dealing only with the variable of EI have not discussed its relationship with cultural adjustment at length.

Moon (2010) supported this claim, saying that a higher degree of emotional intelligence influences the capability of an individual to interact with locals of the host nation. Previous researchers have supported the correlation of emotional

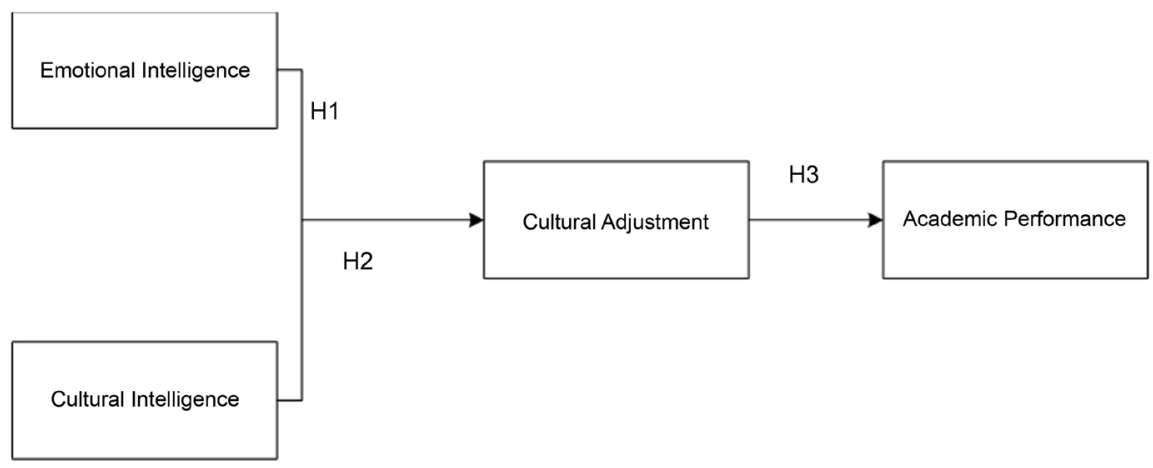

Figure 1. Conceptual model. 
intelligence and cultural adjustment to be positive e.g. Yoo et al. (2006) indicated that emotional recognition ability, which is a component of emotional intelligence is significantly helpful for overseas students when adjusting to a different environment as it can help control the feelings of negativity and distress which an individual is bound to feel in a different environment. Lillis \& Tian (2009) say that people who have a greater degree of emotional intelligence are more sensitive and aware of differences between different cultures and this helps them to reduce miscommunication when interacting with host country nationals. Hence, it is safe to conclude that emotional intelligence, using its four scopes, can aid humans to monitor behaviors and show feelings in a suitable manner to avoid misunderstandings and adjust better in a new cultural environment.

$\mathrm{H1}$ : Emotional intelligence is significantly correlated to cultural adjustment.

\subsubsection{Effects of Cultural Intelligence on Cultural Adjustment}

Recently, the studies being conducted on cultural intelligence are not merely speaking of CQ and its four dimensions but also finding its relationships with various other variables. The experiential study of "international assignment success and cross-cultural adjustment" was meant to increase the understanding regarding the relationship of the different components of CQ and how it affects the adjustment of humans in a diverse environment (i.e. general, interaction and work adjustment).

Many researches have been conducted that focuses on the motivational and behavioral CQ and its correlation with the cultural adjustment of individuals (Lin et al., 2012). Empirical research increased our knowledge of the significance of the motivational element of CQ regarding the adjustment of work and general living among international individuals in a cross-cultural environment. It was claimed by Templer, Tay, \& Chandrasekar (2006) that the motivational component of CQ has more of an effect on the way an individual adjusts to a new cultural setting. It was found by Ang, Van Dyne, Koh, \& Ng (2004) that general adjustment relates to motivational CQ beyond the role of age, gender, and citizenship. This research was conducted on executives who had sufficient prior overseas work experience. Ang et al. (2007) established that both behavioral and motivational CQ are significantly correlated with cultural adjustment. Lee and Sukoco (2007) say that among the four components of CQ, the components of cognitive, motivational and behavioral CQ have a significant correlation with all three components of cultural adjustment, namely, general, work and interaction adjustment of an expatriate. These results indicate that an individual with a greater degree of CQ will most likely adjust more easily in a cross-cultural environment instead of one with a lower degree of CQ.

Examining the above empirical research, it is safe to say that sufficient research has been conducted on the motivational and behavioral aspects of CQ in relation to adjustment, but there are few studies available on the cognitive and meta-cognitive aspects of CQ and their relationship with cultural adjustment. 
Ang et al. (2007) say that this is due to the fact that even if an individual has sufficient information and knowledge of the culture, it does not necessarily mean that information will translate into appropriate actions and behaviors. One must be equipped with information, motivation and the ability to utilize the information and respond in a socially suitable way (Earley \& Peterson, 2004).

Even though a few studies focus more on motivational and behavioral CQ and neglect cognitive and metacognitive CQ, all four components of cultural intelligence proposed by (Earley and Ang, 2003) are important to analyze the competency of humans to adjust to a unique social environment. An individual with a higher level of all four components of cultural intelligence will possess the longing to make peace with the situation and have the determination to constantly use the information in order to create tactics (cognitive and meta-cognitive CQ) and will be eager to respond in a culturally appropriate verbal and non-verbal behavior (motivational and behavioral CQ) (Lin et al., 2012). CQ should predict how well a person adjusts in a cross-cultural environment. Hence, we formulate the hypothesis between CQ and cultural adjustment.

$\mathrm{H}$ 2: Cultural intelligence is significantly correlated to cultural adjustment.

\subsubsection{Effects of Cultural Adjustment on Academic Performance and as a Mediator between EI, CQ and Academic Performance}

When entering a new country for higher studies, international students usually face a number of problems and challenges that include, but are not limited to, social environment, academic environment, language, communication, non-verbal behavior, food, clothing, residence, work environment, health insurance etc. (Nasir, 2012). How well an individual deals with these changes would surely have an impact upon his/her performance academically. It is safe to say that a person who easily adjusts to a cross-cultural environment will perform well as compared to one who suffers and finds it hard to adjust translating to a lower academic achievement. Nasir (2011) says that cultural adjustment is a vital predictor of successful completion of study program of international students.

Few research has been conducted on the mediating effect of cultural adjustment between emotional intelligence, cultural intelligence and the academic outcome of undergraduate, graduate and post-graduate students combined; although positive relationships have been found among the relationship of EI and cultural adjustment, CQ and cultural adjustment, and cultural adjustment and student performance individually (Moon, 2010; Yoo et al., 2006; Earley and Ang, 2003; Gabel, Dolen, and Cerdin, 2005; Reynolds and Constantine, 2007).

Many studies have been conducted with the focus point as international students and the problems they face when studying abroad in an environment slightly different from that of their home country (Gong, 2003; Swagler and Ellis, 2003; Mehdizadeh and Scott, 2005; Blake, 2006; Wester, Kuo, and Vogel, 2006; Poyrazli and Grahame, 2007). Studies have shown that cultural adjustment has a positive relationship with academic outcomes e.g. Chen, Robin, \& Li (1997) found that the way adolescent students adjust socially have an impact on their 
overall academic performance; Gabel, Dolen, \& Cerdin (2005) opined that an individual's ability to adjust in a culturally and socially different environment can predict success in international assignments of expatriates; Reynolds \& Constantine (2007) found that a significant relationship exists between cultural adjustment of students and the outcomes of their career development. The mediating role of cultural adjustment on emotional intelligence, cultural intelligence and Academic performance of international students are depicted in Figure 2 and Figure 3. Therefore we propose the following hypothesis:

H3: Cultural adjustment is significantly correlated to academic performance.

H4: Cultural adjustment acts as a significant mediator between Emotional intelligence and Academic performance.

H5: Cultural adjustment acts as a significant mediator between Cultural Intelligence and Academic performance.

\subsection{Sample Size and Data Collection}

A survey-based closed ended questionnaire was used for collecting data for our study. The sample size for our study was determined using Taro Yamane (1967) sample size formula:

$$
\begin{gathered}
n=\frac{N}{1+N *(e)^{2}} \\
n=\frac{500}{1+500 \times(0.05)^{2}}=222.22 \sim 222
\end{gathered}
$$

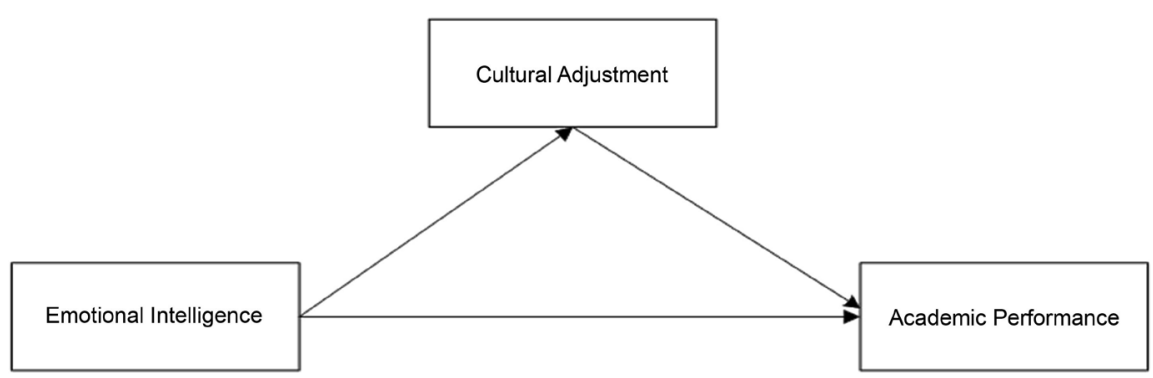

Figure 2. Mediating role of cultural adjustment between EI and academic performance.

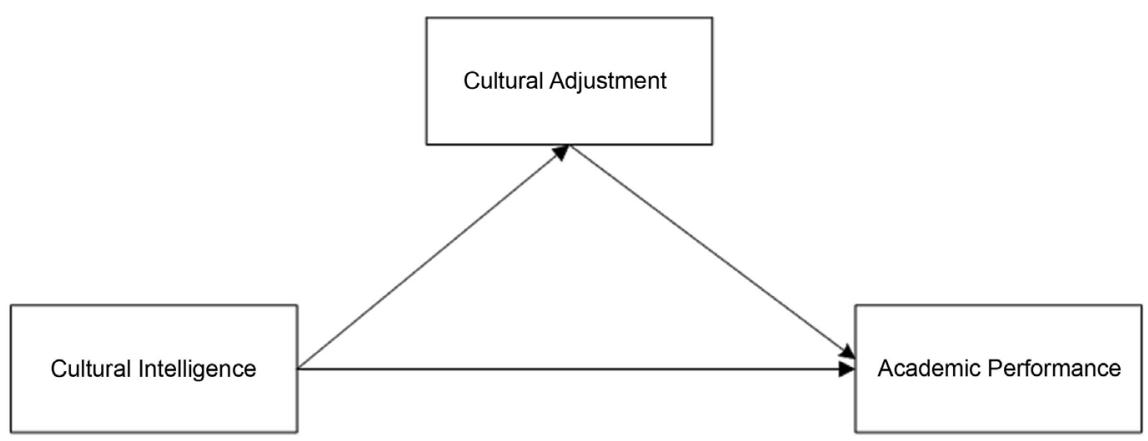

Figure 3. Mediating role of cultural adjustment between $\mathrm{CI}$ and academic performance. 
where:

$n=$ sample size.

$N=$ population of the study.

$e=$ error term (which was 5\%).

The population from which the sample size was drawn from was 500. A total of 222 questionnaires were sent out for data collection and only 202 were rightly filled and useable. The effective recovery rate was $91 \%$.

\subsection{Questionnaire Design and Measures}

Emotional Intelligence: The emotional intelligence scale used in the survey was drawn from Wong and Law (2002). It included 16 items in total for all four of its components (self-emotion appraisal, others' emotion appraisal, use of emotion, and regulation of emotion) divided into 4 questions each for every individual dimension. These items were evaluated by using a 7-point Likert scale ranging from $1=$ strongly disagree to $7=$ strongly agree. Students rating high on this scale indicated that they had the capacity to better comprehend their own feelings, the feelings of others, and control emotions in a better way.

Cultural Intelligence: The cultural intelligence scale used was drawn from Ang et al. (2007). It included 20 items in total which were divided upon the four dimensions; 4 items for metacognitive CQ, 6 items for cognitive CQ, 5 items for motivational CQ, 5 items for behavioral CQ. The items were measured on a 7 -point Likert scale ranging from $1=$ strongly agree to $7=$ strongly disagree. A person rating high on this scale indicated his/her capabilities to better understand a new cultural environment, and behave and respond appropriately according to that environment.

Cultural Adjustment: Cultural adjustment scale was drawn from Black (1988). It included 11 items in total, divided upon the three dimensions of cultural adjustment (general adjustment, interaction adjustment, and work adjustment). These items were measured on a 7-point Likert scale ranging from $1=$ not adjusted at all to $7=$ very well adjusted. An individual rating high on this scale exhibited the capabilities to better adjust to a new culture, have better social relations with the host country's natives and better work adjustment.

Academic Performance: In order to measure academic performance, the scale was adopted from Duncan \& McKeachie (2005). We included 33 items in total which were divided as 16 items for motivation scales and 17 items for learning strategies scale. These items were measured on a 7-point Likert scale ranging from $1=$ not at all true of me to $7=$ very true of me. Students rating high on this scale exhibited a better academic performance than those who scored lower.

\section{Results and Discussion}

Multiple regression analysis using Andrew F. Hayes process version 3.5 and correlation analysis was used to analyze our data. Descriptive statistics was also 
performed on the demographic characteristics of respondents under study using IBM SPSS version 25.0.

Table 1 represents the demographic characteristics of respondents in this study. It shows that 125 respondents were male and 77 were female representing $61.90 \%$ and $38.10 \%$ respectively. 33 respondents were undergraduate students, 65 were graduate students and 104 were postgraduate students constituting a percentage of $16.30 \%, 32.20 \%$ and $51.50 \%$ respectively. Also 23 respondents were between the ages of $16-20$ years representing $11.40 \%, 126$ respondents between the ages of 21 - 25 years representing $62.40 \%, 36$ respondents were between the ages of 26 - 30 years representing $17.80 \%, 11$ respondents were between the ages of $31-35$ years representing $5.40 \%$ and 6 respondents were between the ages of 36 - 40 years representing $3 \%$.

\subsection{Reliability of Study}

Reliability refers to the ability of a questionnaire to consistently measure an attribute and how well the items fit together (Hinton, 2014). To measure the reliability of the questionnaire used for our study, we used internal consistency reliability measure. According to Cortina (1993), Devon et al. (2007), and Nunnally \& Bernstein (1994) conceptually, internal consistency reliability measure examines the average inter-term correlations within a variable and indicates how well the items fit together. SPSS 25.0 was used to estimate the Cronbach's alpha coefficient to measure the internal consistency of our questionnaire. Cronbach's alpha is the most prevalent reliability statistic used by many researchers to estimate internal consistency reliability (Devon et al., 2007; Adamson \& Prion, 2013). Cronbach $\alpha$ coefficients range between 0 - 1 and a value of $\geq 0.70$ indicates a good reliability (Bland \& Altman, 1997). As shown in Table 2, the estimated Cronbach $\alpha$ value ranged between $0.836-0.946$ for all subscales and total scale of measurement variables indicating a high correlation between the items and the questions, therefore the questionnaire used for our study was consistently reliable.

\subsection{Construct Validity}

The validity of a study refers to how accurate are the measurement results. Factor analysis was performed to establish the construct validity of our questionnaire using the Kaiser-Meyer-Olkin (KMO) and Bartlett's Test of Sphericity measures. KMO measures if the responses given to the questionnaire for our study were adequate or not. Kaiser (1974) recommended a KMO estimate of 0.5 as the minimum for a satisfactory factor analysis. Table 3 shows that the minimum KMO value was achieved with a value of 0.78 , indicating the adequacy of our sampling.

Bartlett's Test of Sphericity measures the strength of the relationship among the variables under study. The null hypothesis for this test is that "The correlation matrix is an identity matrix". Results from the analysis as shown in Table 3 indicates a statistical significance for the Bartlett's test with a $P$-value of 0.00 and 
Table 1. Demographic characteristics of respondents.

\begin{tabular}{ccc}
\hline Demographic Characteristic & Responses & Percentage (\%) \\
Gender & 125 & 61.90 \\
Male & 77 & 38.10 \\
Female & 202 & 100 \\
Total & & \\
Educational Background & 33 & 16.30 \\
Undergraduate & 65 & 32.20 \\
Graduate & 104 & 51.50 \\
Post-graduate & 202 & 100 \\
Total & & \\
Age & 23 & 11.40 \\
16 - 20 years & 126 & 62.40 \\
21 - 25 years & 36 & 17.80 \\
26 - 30 years & 11 & 5.40 \\
31 - 35 years & 6 & 3.0 \\
36 - 40 years & 202 & 100 \\
Total & & \\
\hline
\end{tabular}

Source: Field Survey, 2020.

Table 2. Results of reliability test.

\begin{tabular}{ccc}
\hline Variable & No of items & Cronbach $\alpha$ \\
\hline Emotional Intelligence & 16 & 0.84 \\
Cultural Intelligence & 20 & 0.90 \\
Cultural Adjustment & 11 & 0.88 \\
Academic Performance & 33 & 0.90 \\
Total scale of variables & 80 & 0.95 \\
\hline
\end{tabular}

Table 3. Construct validity test result.

\begin{tabular}{ccc}
\hline Test & Measure & Estimate \\
\hline Kaiser-Meyer-Olkin Measure of Sampling Adequacy & & 0.78 \\
& Approx. Chi-square & 213.52 \\
Bartlett's Test of Sphericity & df & 6 \\
& Sig. & 0.00 \\
\hline
\end{tabular}

an approx. chi-square of 213.52, consequently, we reject the null hypothesis that the correlation matrix is an identity matrix.

\subsection{Pearson's Correlation}

Pearson's correlation coefficient statistic measures the statistical association be- 
tween two continuous or quantitative variables (Rodgers \& Nicewander, 1988). This test statistic uses the method of covariance to measure the relationship between two continuous variables of interest by providing the magnitude and the direction of the relationship (Wackerly et al., 2008). The Pearson's correlation tests the null hypothesis that "There is no linear relationship between the two variables $(\rho=0)$ " and alternative hypothesis "There is a linear relationship between the two variables $(\rho \neq 0)$ ". The correlation coefficient ranges between -1 and +1 . A correlation coefficient of zero indicates no linear relationship exists between the two variables under study and correlation coefficient of -1 or +1 indicates a perfect linear association (all data points lie exactly on the straight line). The general criteria for judging the magnitude and direction of the correlation coefficients according to Mukaka (2012), and Overholser \& Sowinski (2008) are as follows: a correlation coefficient between $0.00-0.10$ indicates negligible correlation, between 0.10 - 0.39 indicates weak correlation, between 0.40 0.69 indicates Moderate correlation, and between 0.70 - 0.89 indicates Strong correlation and a value between 0.90 - 1.00 indicates a very strong correlation. From Table 4, all the correlation coefficients are above $0.00(0.42-0.54)$ indicating a form of association between the variables and also all the variables are significantly correlated since all the $p$-values are less than 0.05 .

\subsection{Multiple Regression Analysis (Andrews F. Hayes Process)}

A multiple regression analysis was performed using Andrew F. Hayes process macro (version 3.5) to measure the mediating effect of Cultural Adjustment on Cultural Intelligence, Emotional Intelligence and Academic Performance. The results from the analysis are shown in Table 5 and Table 6.

Table 4. Correlation analysis.

\begin{tabular}{|c|c|c|c|c|c|}
\hline Variable & Measure & $\begin{array}{c}\text { Academic } \\
\text { Performance }\end{array}$ & $\begin{array}{c}\text { Cultural } \\
\text { Intelligence }\end{array}$ & $\begin{array}{l}\text { Emotional } \\
\text { Intelligence }\end{array}$ & $\begin{array}{c}\text { Cultural } \\
\text { Adjustment }\end{array}$ \\
\hline \multirow{3}{*}{$\begin{array}{c}\text { Academic } \\
\text { Performance }\end{array}$} & Pearson Correlation & 1 & $0.54^{\star *}$ & $0.47^{\star *}$ & $0.54^{\star *}$ \\
\hline & Sig. (2-tailed) & & 0.000 & 0.000 & 0.000 \\
\hline & $\mathrm{N}$ & 202 & 202 & 202 & 202 \\
\hline \multirow{3}{*}{$\begin{array}{c}\text { Cultural } \\
\text { Intelligence }\end{array}$} & Pearson Correlation & $0.54^{* *}$ & 1 & $0.42^{* *}$ & $0.44^{* *}$ \\
\hline & Sig. (2-tailed) & 0.000 & & 0.000 & 0.000 \\
\hline & $\mathrm{N}$ & 202 & 202 & 202 & 202 \\
\hline \multirow{3}{*}{$\begin{array}{l}\text { Emotional } \\
\text { Intelligence }\end{array}$} & Pearson Correlation & $0.47^{\star *}$ & $0.42^{\star *}$ & 1 & $0.44^{\star *}$ \\
\hline & Sig. (2-tailed) & 0.000 & 0.000 & & 0.000 \\
\hline & $\mathrm{N}$ & 202 & 202 & 202 & 202 \\
\hline \multirow{3}{*}{$\begin{array}{c}\text { Cultural } \\
\text { Adjustment }\end{array}$} & Pearson Correlation & $0.53^{\star *}$ & $0.44^{\star *}$ & $0.44^{\star *}$ & 1 \\
\hline & Sig. (2-tailed) & 0.000 & 0.000 & 0.000 & \\
\hline & $\mathrm{N}$ & 202 & 202 & 202 & 202 \\
\hline
\end{tabular}

${ }^{*}$ Correlation is significant at the 0.01 (2-tailed). 
Table 5. Mediating effect of cultural adjustment on emotional intelligence and academic performance.

\begin{tabular}{cccccc}
\hline Academic Performance & Estimate & $\mathbf{t}$ & SE & R-square & $P$-value \\
\hline Constant & 177.50 & 140.41 & 1.26 & & $* * *$ \\
Emotional Intelligence & 6.52 & 4.63 & 1.41 & & $* * *$ \\
Cultural Adjustment & 9.03 & 6.42 & 1.41 & 0.35 & $* * *$ \\
Total effect & 10.46 & 7.53 & 1.39 & & \\
Indirect Effect & 3.94 & & & \\
BootSE & 0.91 & & & \\
BootLLCI & 2.29 & & & \\
BootULCI & 5.80 & & & \\
\hline
\end{tabular}

${ }^{* * *} P<0.001$ (Significant).

Table 6. Mediating effect of cultural adjustment on cultural intelligence and academic performance.

\begin{tabular}{cccccc}
\hline Academic Performance & Estimate & $\mathbf{t}$ & SE & R-square & $P$-value \\
\hline Constant & 177.50 & 145.84 & 1.22 & & $* * *$ \\
Cultural Intelligence & 8.47 & 6.23 & 1.36 & & $* * *$ \\
Cultural Adjustment & 8.14 & 5.99 & 1.36 & 0.40 & $* * *$ \\
Total effect & 12.06 & 9.12 & 1.32 & & \\
Indirect Effect & 3.59 & & & \\
BootSE & 0.78 & & & \\
BootLLCI & 2.16 & & & \\
BootULCI & 5.21 & & & \\
\hline
\end{tabular}

${ }^{* * *} P<0.001$ (Significant).

\subsection{Hypothesis Testing}

$\mathrm{H1}$ : Emotional intelligence is significantly correlated to cultural adjustment.

The result in Table 4 indicates a significant moderate relationship between cultural intelligence and cultural adjustment with a correlation coefficient of 0.44 . This association between the two variables is statistically significant with a $p$-value of 0.00 . This significant association is further stressed on by the research work of Chen et al. (2006), Bar-On (2000), and Kim et al. (2008) that, emotional intelligence plays a vital role in the adjustment of individuals to their environment. With the aid of emotion and information, it becomes easier for an individual to grasp cultural norms of the host nation and to interact with local people. Emotional intelligence is significantly helpful for overseas students when adjusting to a different environment as it can help control the feelings of negativity and distress which an individual is bound to feel in a different environment. It also helps them to reduce miscommunication when interacting with host country nationals. 
Consequently, we accept our hypothesis $\mathrm{H} 1$ that emotional intelligence is significantly associated with cultural adjustment. This result also indicates that international students with a higher degree of emotional intelligence are likely to adjust and adapt to new environment very well.

H2: Cultural intelligence is significantly correlated to cultural adjustment.

The correlation coefficient between cultural intelligence and cultural adjustment is 0.44 indicating a moderate association. The relationship is positive and statistically significant with a $p$-value of 0.000 as shown in Table 4. Result from this analysis is consistent with the research work of Chen et al. (2006), Lee \& Sukoco (2007), Ang et al. (2007), and Templer et al. (2006), they opined that cultural intelligence is significantly correlated to cultural adjustment.

An individual with a higher level of all four components of cultural intelligence will possess the longing to make peace with the situation and have the determination to constantly use the information in order to create tactics (cognitive and meta-cognitive $\mathrm{CQ}$ ) and will be eager to respond in a culturally appropriate verbal and non-verbal behavior (motivational and behavioral CQ).

Therefore we accept our hypothesis $\mathrm{H} 2$ and conclude that, international students with greater degree of cultural intelligence are more likely to adjust in a cross-cultural environment.

H3: Cultural adjustment is significantly correlated to academic performance.

Result analysis indicates a moderate significant association between cultural adjustment and academic performance with a correlation coefficient of 0.53 . This relationship is statistically significant with a $p$-value of 0.00 . Previous researches have revealed the significant positive relationship between cultural adjustment and academic performance indicating that individuals who are well adjusted in new environments tend to perform very well (Reynolds \& Constantine, 2007; Gabel et al., 2005; Chen et al., 1997). How well an individual adjusts to numerous differences between two cultures such as social environment, academic environment, language, communication, non-verbal behavior, food, clothing, residence, work environment, health insurance etc. determines how well he/she performs academically. A well-rounded adjustment will result in a better academic performance just as an uneasy or difficult adjustment will translate into lower academic achievements.

Based on our results, we accept our hypothesis $\mathrm{H} 3$ that cultural adjustment is significantly correlated to academic performance.

H4: Cultural adjustment acts as a significant mediator between Emotional intelligence and Academic performance.

The direct effects of emotional intelligence and cultural adjustment on academic performance are all statistically significant with $p$-values of 0.000 each as shown in Table 5. The total effect of emotional intelligence and cultural adjustment on predicting academic performance was also statistically significant with t-value and $p$-value of 7.53 and 0.000 respectively. The indirect effect, which represents the mediating effect, has a value of 3.94 with Boot Lower Level Confidence Interval (BootLLCI) and Boot Upper Level Confidence Interval (Boo- 
tULCI) of 2.29 and 5.80 respectively. This effect is statistically significant since zero (0) lies outside the estimated confidence interval $(2.29,5.80)$. An individual having sufficient knowledge about how to use, understand and respond to the emotions and feelings of oneself as well as others, in relation to having adjusted to a culturally diverse environment will have a ten-fold effect upon his/her education as they will know how to interact effectively with the locals and use that to make sense of the surroundings as well as aid in educational context.

Consequently, we accept our hypothesis $\mathrm{H} 4$ that, cultural adjustment significantly mediates the effect between emotional intelligence and academic performance of international students.

H5: Cultural adjustment acts as a significant mediator between Cultural Intelligence and Academic performance.

Results in Table 6 indicate a significant mediating effect of cultural adjustment on emotional intelligence and academic performance. The direct effects of cultural intelligence and cultural adjustment on academic performance are all statistically significant with $p$-values of 0.000 each. The total effect of cultural intelligence and cultural adjustment on predicting academic performance was also statistically significant with t-value and $p$-value of 9.12 and 0.000 respectively. The indirect effect, which represents the mediating effect, has a value of 3.59 with Boot Lower Level Confidence Interval (BootLLCI) and Boot Upper Level Confidence Interval (BootULCI) of 2.16 and 5.21 respectively. This effect is statistically significant since zero (0) lies outside the estimated confidence interval $(2.16,5.21)$. When a person's knowledge about the culture where he is going is paired with the adjustment, it increases his chances of having a better and a satisfactory life in that environment. This satisfactory environment also has a positive and significant effect upon international students' daily activities as well as educational achievements.

Consequently, we accept our hypothesis H5 that, cultural adjustment significantly mediates the effect between cultural intelligence and academic performance of international students.

\section{Conclusion}

This study was conducted to examine the effects of emotional intelligence and cultural intelligence on the academic performance of international students with cultural adjustment as a mediator. The data was collected from a diverse pool of respondents who are enrolled as international students away from their home countries. Our study concludes that the relationships between the variables selected for this research were positive and significant with moderate associations.

This research proves that an individual with a greater degree of emotional intelligence is more likely to recognize one's own feelings, others' feelings, manage one's emotions and use them in an appropriate manner to adjust to a new cultural environment easily and perform better academically. Our study also showed a significant correlation between cultural adjustment and academic performance. A person having a greater degree of cultural intelligence has a greater 
drive to pursue knowledge regarding different cultures and use that information to behave accordingly when engaging with people in a different cultural environment, thereby managing personal relationships in a better way to facilitate educational life. Moreover, this study proved cultural adjustment to be a significant mediator and showed that the better an individual is adjusted to a changed environment, workplace and people; the better he performed academically with exceptional results.

There are also multiple implications of this study. This research can be used by different universities across the world that have foreign exchange programs and that are open to international students so that they may incorporate it into their tests in order to understand the emotional and cultural intelligence level of the students. This will help them to determine which student is a better fit for the university and further assist them to attain results academically. Moreover, this paper can also be used by educational ministries in different countries to help the universities adopt an effective foreign exchange program to facilitate the international students and help them perform effectively. This framework can also be used by international students to help them analyze where they fit better and which culture suits them the best where they will flourish academically.

This study is also subjected to some limitations. We conducted our research on a cross-sectional basis and the derived results were based purely on quantitative analysis. Further researchers can conduct a longitudinal study to get a better understanding regarding these variables and how they change over time when there is a cultural effect upon the students. Moreover, a qualitative analysis will also be helpful as it will be more descriptive and help the researchers gain a better understanding about the students and how they feel. Furthermore, future researchers can employ a larger sample size to get further diversified results which will lead to a better holistic analysis.

\section{Conflicts of Interest}

The authors declare no conflicts of interest regarding the publication of this paper.

\section{References}

Abbott-Chapman, J., Hughes, P., \& Wyld, C. (1992). Monitoring Student Progress: A Framework for Improving Student Performance and Reducing Attrition in Higher Education. Hobart: National Clearinghouse for Youth Studies.

Abdul Malek, M., \& Budhwar, P. (2013). Cultural Intelligence as a Predictor of Expatriate Adjustment and Performance in Malaysia. Journal of World Business, 48, 222-231. https://doi.org/10.1016/j.jwb.2012.07.006

Adamson, K. A., \& Prion, S. (2013). Reliability: Measuring Internal Consistency Using Cronbach's a. Clinical Simulation in Nursing, 9, E179-E180. https://doi.org/10.1016/j.ecns.2012.12.001

Adeyemo, D. A. (2006). The Buffering Effect of Emotional Intelligence on the Adjustment of Secondary School Students in Transition. Electronic Journal of Research in Educational Psychology, 3, 79-90. 
Ang, S., Van Dyne, L., \& Koh, S. K. (2006). Personality Correlates of the Four-Factor Model of Cultural Intelligence. Group and Organization Management, 31, 100-123. https://doi.org/10.1177/1059601105275267

Ang, S., Van Dyne, L., Koh, C., \& Ng, K. Y. (2004). The Measurement of Cultural Intelligence. In 2004 Academy of Management Meetings Symposium on Cultural Intelligence in the 21st Century. New Orleans.

Ang, S., Van Dyne, L., Koh, C., Ng, K. Y., Templer, K. J., Tay, C. et al. (2007). Cultural Intelligence: Its Measurement and Effects on Cultural Judgment and Decision Making, Cultural Adaptation and Task Performance. Management and Organisation Review, 3, 335-371. https://doi.org/10.1111/j.1740-8784.2007.00082.x

Bar-On, R. (2000). Emotional and Social Intelligence: Insights from the Emotional Quotient Inventory. In R. Bar-On, \& J. D. A. Parker (Eds.), The Handbook of Emotional Intelligence (pp. 363-388). San Francisco, CA: Josey-Bass.

Bar-On, R. (2004). EQ-i: Bar-On Emotional Intelligence Quotient Inventory Technical Manual. Toronto: Multi-Health Systems.

Biggs, J. B. (1987). Student Approaches to Learning and Studying. Victoria: Australian Council for Educational Research.

Black, J. S. (1988). Work Role Transitions: A Study of American Expatriate Managers in Japan. Journal of International Business Studies, 19, 277-294. https://doi.org/10.1057/palgrave.jibs.8490383

Black, J. S., Mendenhall, M., \& Oddou, G. (1991). Toward a Comprehensive Model of International Adjustment: An Integration of Multiple Theoretical Perceptive. Academy of Management Review, 16, 291-317. https://doi.org/10.5465/amr.1991.4278938

Blake A. C. (2006). The Experiences and Adjustment Problems of Africans at a Historically Black Institution. College Student Journal, 40, 808-813. http://findarticles.com/p/articles/mi_m0FCR/is_4_40/ai_n27094505

Bland, J. M., \& Altman, D. G. (1997). Statistics Notes: Cronbach's Alpha. BMJ, 314, 572. https://doi.org/10.1136/bmj.314.7080.572

Cartwright, S., \& Pappas, C. (2008). Emotional Intelligence, Its Measurement and Implications for the Workplace. International Journal of Management Reviews, 10, 149-171. https://doi.org/10.1111/j.1468-2370.2007.00220.x

Chen, F. S. et al. (2006). A Study of the Emotional Intelligence and Life Adjustment of Senior High School Students. World Transactions on Engineering and Technology Education, 5, 473-476.

Chen, X., Rubin, K. H., \& Li, D. (1997). Relation between Academic Achievement and Social Adjustment: Evidence from Chinese Children. Developmental Psychology, 33, 518-525. https://doi.org/10.1037/0012-1649.33.3.518

Chopra, R. (2005). Academic Dictionary of Psychology. Delhi: Isha Books.

Constantine, M. G. et al. (2004). Self-Concealment, Social Efficacy, Acculturative Stress and Depression in African, Asian and Latin America International College Students. American Journal of Orthopsychiatry, 74, 230-241.

https://doi.org/10.1037/0002-9432.74.3.230

Cortina, J. M. (1993). What Is Coefficient Alpha? An Examination of Theory and Applications. Journal of Applied Psychology, 78, 98-104.

https://doi.org/10.1037/0021-9010.78.1.98

Devon, H. A., Block, M. E., Moyle-Wright, P., Ernst, D. M., Hayden, S. J., Lazzara, D. J., Savoy, S. M., \& Kostas-Polston, E. (2007). A Psychometric Toolbox for Testing Validity and Reliability. Journal of Nursing Scholarship, 39, 155-164. 
https://doi.org/10.1111/j.1547-5069.2007.00161.x

Duff, A., Boyle, E., Dunleavy, K., \& Ferguson, J. (2004). The Relationship between Personality, Approach to Learning and Academic Performance. Personality and Individual Differences, 36, 1907-1920. https://doi.org/10.1016/j.paid.2003.08.020

Duncan, T. G., \& McKeachie, W. J. (2005). The Making of the Motivated Strategies for Learning Questionnaire. Educational Psychologist, 40, 117-128. https://doi.org/10.1207/s15326985ep4002_6

Earley, P. C., \& Ang, S. (2003). Cultural Intelligence: Individual Interactions across Cultures. Stanford, CA: Stanford University Press.

Earley, P. C., \& Mosakowski, E. (2005). Cultural Intelligence. Harvard Business Review, $82,139-153$.

Earley, P. C., \& Peterson, R. S. (2004). The Elusive Cultural Chameleon: Cultural Intelligence as a New Approach to Intercultural Training for the Global Manager. Academy of Management Learning and Education, 3, 100-115. https://doi.org/10.5465/amle.2004.12436826

Engelberg, E., \& Sjoberg, L. (2004). Emotional Intelligence, Affect Intensity and Social Adjustment. Personality and Individual Differences, 37, 533-542. https://doi.org/10.1016/j.paid.2003.09.024

Evans, H. T. (2007). A Phenomenological Study: The Benefits of Self-Regulation Regarding Student Achievement, Social Adjustment, and Empowerment. Phoenix: University of Phoenix.

Gabel, R. S., Dolan, S. L., \& Cerdin, J. L. (2005). Emotional Intelligence as Predictor of Cultural Adjustments for Success in Global Assignments. Career Development International, 10, 375-395. https://doi.org/10.1108/13620430510615300

Goleman, D. (1995). Emotional Intelligence. New York: Bantam Books.

Goleman, D. (1996). Emotional Intelligence: Why It Can Matter More than IQ. London: Bloomsbury.

Gong, Y. (2003). Goal Orientations and Cross-Cultural Adjustment: An Exploratory Study. International Journal of Intercultural Relations, 27, 297-305.

https://doi.org/10.1016/S0147-1767(03)00013-0

Head, P. (1990). Performance Indicators and Quality Assurance. London: Council for National Academic Awards.

Hinton, P. R. (2014). Statistics Explained. Abingdon-on-Thames! Routledge. https://doi.org/10.4324/9781315797564

Kagan, H., \& Cohen, J. (1990). Cultural Adjustment of International Students. Psychological Science, 1, 133-137. https://doi.org/10.1111/j.1467-9280.1990.tb00082.x

Kaiser, H. F. (1974). An Index of Factorial Simplicity Psychometrics. Psychometrika, 39, 31-36. https://doi.org/10.1007/BF02291575

Kerr, S. et al. (2004). Predicting Adjustment during the Transition to College: Alexithymia, Perceived Stress, and Psychological Symptoms. Journal of College Student Development, 45, 593-611. https://doi.org/10.1353/csd.2004.0068

Kim, K., Kirkman, B. L., \& Chen, G. (2008). Cultural Intelligence and International Assignment Effectiveness: A Conceptual Model and Preliminary Findings. In Annual Meeting of the Academy of Management (pp. 71-90). New York: M. E. Sharpe. https://doi.org/10.5465/ambpp.2006.27162843

Lee, L., \& Sukoco, B. M. (2007). The Effects of Expatriate Personality and Cultural Intelligence on the Expatriate Adjustment: The Mediating Role of Expatriate. In 13th Asia 
Pacifica Management Conference (pp. 922-931). Melbourne.

Li, G., Chen, W., \& Duanmu, J. L. (2010). Determinants of International Students' Academic Performance: A Comparison between Chinese and Other International Students. Journal of Studies in International Education, 14, 389-405. https://doi.org/10.1177/1028315309331490

Lillis, M. P., \& Tian, R. G. (2009). Cross-Cultural Communication and Emotional Intelligence: Inferences from Case Studies of Gender Diverse Groups. Marketing Intelligence and Planning, 27, 428-438. https://doi.org/10.1108/02634500910955272

Lin, Y. C., Chen, A. S. Y., \& Song, Y. C. (2012). Does Your Intelligence Help to Survive in a Foreign Jungle? The Effects of Cultural Intelligence and Emotional Intelligence on Cross-Cultural Adjustment. International Journal of Intercultural Relations, 36, 541-552. https://doi.org/10.1016/j.ijintrel.2012.03.001

Marsh, A. A., Elfenbein, H. A., \& Ambady, N. (2003). Nonverbal “Accents”: Cultural Differences in Facial Expressions of Emotion. Psychological Science, 14, 373-376. https://doi.org/10.1111/1467-9280.24461

Mayer, J. D., \& Salovey, P. (1997). What Is Emotional Intelligence?” In P. Salovey, \& D. Sluyter (Eds.), Emotional Development and Emotional Intelligence: Educational Implications (pp. 3-34). New York: Basic Books.

McKenzie, K., \& Schweitzer, R. (2001). Who Succeeds at University? Factors Predicting Academic Performance in First Year Australian University Students. Higher Education Research and Development, 20, 21-33. https://doi.org/10.1080/07924360120043621

McKenzie, K., Gow, K., \& Schweitzer, R. (2004). Exploring First Year Academic Achievement through Structural Equation Modelling. Higher Education Research and Development, 23, 95-112. https://doi.org/10.1080/0729436032000168513

Mehdizadeh, N., \& Scott, G. (2005). Adjustment Problems of Iranian International Students in Scotland. International Education Journal, 6, 484-493.

Moon, T. (2010). Emotional Intelligence Correlates of the Four-Factor Model of Cultural Intelligence. Journal of Managerial Psychology, 25, 876-898. https://doi.org/10.1108/02683941011089134

Mount, C., \& Downton, C. (2006). Alzheimer Disease: Progress or Profit? Nature Medicine, 12, 780-784. https://doi.org/10.1038/nm0706-780

Mukaka, M. M. (2012). Statistics Corner: A Guide to Appropriate Use of Correlation Coefficient in Medical Research. Malawi Medical Journal, 24, 69-71.

Nasir, M. (2011). Correlation of Emotional Intelligence with Demographic Characteristics, Academic Achievement and Cultural Adjustment of the Students of IIUI. Unpublished Doctorate Thesis, International Islamic University Islamabad.

Nasir, M. (2012). Effects of Cultural Adjustment on Academic Achievement of International Students. Journal of Elementary Education, 22, 95-103.

Nunnally, J., \& Bernstein, I. (1994). Psychometric Theory(3rd ed.). New York: McGraw-Hill.

Overholser, B. R., \& Sowinski, K. M. (2008). Biostatistics Preview: Part 2. Nutrition in Clinical Practice, 23, 76-84. https://doi.org/10.1177/011542650802300176

Palthe, J. (2004). The Relative Importance of Antecedents to Cross-Cultural Adjustment: Implications for Managing a Global Workforce. International Journal of Intercultural Relations, 28, 37-59. https://doi.org/10.1016/j.ijintrel.2003.12.004

Parker, B., \& McEvoy, G. M. (1993). Initial Examination of a Model of Intercultural Adjustment. International Journal of Intercultural Relations, 17, 355-379.

https://doi.org/10.1016/0147-1767(93)90039-B

Pokay, P., \& Blumenfeld, P. (1990). Predicting Achievement Early and Late in the Seme- 
ster: The Role of Motivation and Use of Learning Strategies. Journal of Educational Psychology, 82, 41-50. https://doi.org/10.1037/0022-0663.82.1.41

Poyrazli, S., \& Grahame, K. M. (2007). Barriers to Adjustment: Needs of International Students within a Semi-Urban Campus Community.

http://www.redorbit.com/news/education/907480/barriers_to_adjustment_needs_of_in ternational_students_within_a_semiurban/index.html

Reynolds, A. L., \& Constantine, M. G. (2007). Cultural Adjustment Difficulties and Career Development of International College Students. Journal of Career Assessment, 15, 338-350. https://doi.org/10.1177/1069072707301218

Rice, D. M. (2007). An Examination of Emotional Intelligence: Its Relationship to Academic Achievement in Army JROTC and the Implications for Education. Capella University.

Rodgers, J. L., \& Nicewander, W. A. (1988). Thirteen Ways to Look at the Correlation Coefficient. The American Statistician, 42, 59-66. https://doi.org/10.1080/00031305.1988.10475524

Sadler-Smith, E. (1996). Approaches to Studying: Age, Gender and Academic Performance. Educational Studies, 22, 367-380. https://doi.org/10.1080/0305569960220306

Salovey, P., \& Mayer, J. D. (1990). Emotional Intelligence. Imagination, Cognition, and Personality, 9, 185-211. https://doi.org/10.2190/DUGG-P24E-52WK-6CDG

Salovey, P., \& Pizarro, D. (2003). The Value of Emotional Intelligence. In R. J. Sternberg, J. Lautrey, \& T. I. Lubart (Eds.), Models of Intelligence: International Perspectives (pp. 263-278). Washington DC: American Psychological Association.

Shaffer, M. A., Harrison, D. A., \& Gilley, K. M. (1999). Dimensions, Determinants, and Differences in the Expatriate Adjustment Process. Journal of International Business Studies, 30, 557-581. https://doi.org/10.1057/palgrave.jibs.8490083

Simon, J. A., Kelichman, S., \& Santrock, J. W. (1994). Human Adjustment. Madison, WI: Brown and Benchmark Publishers.

Swagler, M. A., \& Ellis, M. V. (2003). Crossing the Distance: Adjustment of Taiwanese Graduate Students in the United States. Journal of Counseling Psychology, 52, 527-536. https://doi.org/10.1037/0022-0167.50.4.420

Templer, K. L., Tay, C., \& Chandrasekar, N. A. (2006). Motivational Cultural Intelligence, Realist Job Preview, Realistic Living Conditions Preview, and Cross-Cultural Adjustment. Group and Organization Management, 31, 154-173. https://doi.org/10.1177/1059601105275293

Thomas, D. C. (2006). Domain and Development of Cultural Intelligence: The Importance of Mindfulness. Group and Organization Management, 31, 78-99. https://doi.org/10.1177/1059601105275266

Thomas, D. C., \& Inkson, K. (2004). Cultivating Your Cultural Intelligence. Security Management, 48, 30-33.

Thorndike, E. L. (1920). Intelligence and Its Uses. Harper's Magazine, 140, 227-235.

Thorndike, R. L. (1936). Factor Analysis of Social and Abstract Intelligence. Journal of Educational Psychology, 27, 231-233. https://doi.org/10.1037/h0059840

Vianen, A. E. M. V., De Pater, I. E., Kristof-Brown, A. L., \& Johnson, E. C. (2004). Fitting in Surface- and Deep-Level Cultural Differences and Expatriates' Adjustment. Academy of Management Journal, 47, 697-709. https://doi.org/10.5465/20159612

Wackerly, D. D., Mendenhall III, W., \& Scheaffer, R. L. (2008). Multivariate Probability Distributions. In Mathematical Statistics with Applications (7th ed., pp. 223-295) Belmont, CA: Brooks/Cole. 
Watkins, D., \& Hattie, J. (1981). The Learning Processes of Australian University Students: Investigations of Contextual and Personological Factors. British Journal of Educational Psychology, 51, 384-393. https://doi.org/10.1111/j.2044-8279.1981.tb02494.x

Wester, S. R., Kuo, B. C. H., \& Vogel, D. L. (2006). Multicultural Coping: Chinese Canadian Adolescents, Male Gender Role Conflict and Psychological Distress. Psychology of Men and Masculinity, 7, 83-100. https://doi.org/10.1037/1524-9220.7.2.83

Wong, C. S., \& Law, L. S. (2002). The Effects of Leader and Follower Emotional Intelligence on Performance and Attitude: An Exploratory Study. The Leadership Quarterly, 13, 243-274. https://doi.org/10.1016/S1048-9843(02)00099-1

Yamane, T. (1967). Statistics: An Introductory Analysis (2nd ed.). New York: Harper and Row.

Yoo, S. H., Matsumoto, D., \& LeRoux, J. A. (2006). The Influence of Emotion Recognition and Emotion Regulation on Intercultural Adjustment. International Journal of Intercultural Relations, 30, 345-363. https://doi.org/10.1016/j.ijintrel.2005.08.006

Yorke, M. (1991). Performance Indicators: Observations on Their Use in the Assurance of Course Quality (CNAA Project Report 30). London: Council for National Academic Awards. 